\title{
ANALISIS PENGARUH FAKTOR KESUKSESAN PENGADOPSIAN E-COMMERCE PADA USAHA KECIL DAN MENENGAH DI KOTA MEDAN
}

\author{
Mutia Arda \\ Delyana R Pulungan \\ Fakultas Ekonomi dan Bisnis, Program Studi Manajemen \\ Universitas Muhammadiyah Sumatera Utara \\ e-mail: mutiaarda@umsu.ac.id
}

\begin{abstract}
Abstrak
Usaha Kecil dan Menengah di Indonesia telah menciptakan peluang kerja yang cukup besar bagi pekerja rumah tangga, sehingga mereka dapat membantu mengurangi pengangguran. Perkembangan teknologi berdampak pada munculnya e-commerce. Keberhasilan e-commerce mulai berkembang seperti kemudahan transaksi yang dapat dilakukan kapan saja dan di mana saja. Tetapi juga tidak sedikit pelaku bisnis yang telah gagal dan beberapa masih belum tahu apakah ecommerce telah mencapai kesuksesan atau tidak. Studi ini akan membandingkan keberhasilan atau kegagalan e-commerce yang sangat ditentukan oleh bagaimana perusahaan dapat meminimalkan faktor penghambat dan memaksimalkan pendorong keberhasilan. Faktor-faktor ini dikelompokkan menjadi 4 faktor, yaitu internal driver,external driver, hambatan internal dan hambatan eksternal. Populasi penelitian ini adalah perusahaan kecil dan menengah di Kota Medan yang sudah memiliki akun e-commerce. Teknik analisis yang digunakan regresi berganda. Hasil pengolahan statistik deskriptif diketahui bahwa mayoritas responden yang menggunakan layanan e-commerce adalah UKM yang bergerak dalam bidang Fashion atau menjual barang-barang seperti pakaian, tas, sepatu. Shopee lebih dipercaya sebagai tempat untuk membantu transaksi antara pembeli dan penjual, bukan platform untuk iklan secara online. Hasil penelitian menunjukkan internal dan external driver berpengaruh positif dan signifikan terhadap keberhasilan e-commerce. Sementara internal obstacles tidak signifikan terhadap keberhasilan e-commerce dan external obstacles secara negatif mempengaruhi keberhasilan e-commerce.
\end{abstract}

Kata kunci : Kesuksesan, E-Commerce, Usaha Kecil dan Menengah (UKM)

Abstract
Small and Medium Enterprises in Indonesia have created considerable employment opportunities for domestic workers, so they can help reduce unemployment. Technology development has an impact on the emergence of e-commerce. The success of e-commerce began to develop like the ease of transactions that can be done anytime and anywhere. But also not a few business people who have failed and some still do not know whether e-commerce has achieved success or not. This study will compare the success or failure of e-commerce which is very much determined by how companies can minimize the inhibiting factors and maximize the drivers of success. These factors are grouped into 4 factors, namely internal drivers, external drivers, internal barriers and external obstacles. The population of this study is small and medium-sized companies in Medan City that already have e-commerce accounts. The analysis technique used is multiple regression. The results of processing descriptive statistics are known that the majority of respondents who use e-commerce services are SMEs engaged in Fashion or selling items such as clothing, bags, shoes. Shopee is more trusted as a place to assist transactions between buyers and sellers, not a platform for online advertising. The results showed that internal and external drivers had a positive and significant effect on the success of e-commerce. While internal obstacles are not significant to the success of e-commerce and external obstacles negatively affect the success of e-commerce.

\section{Keywords : Success, E-Commerce, Small and Medium Enterprises (SMEs)}


Volume 2. No.2 Agustus 2019 (100- 108)

Doi. 10.30596/liabilities.v2i2.3246

\section{PENDAHULUAN}

Salah satu pilar ekonomi nasional yang sekarang menjadi fenomena utama adalah e-commerce atau kegiatan perdagangan melalui dunia maya di mana persentase tingkat pertumbuhan mencapai tertinggi di kawasan Asia Tenggara dan bahkan dunia. Menurut para ekonom, potensi nyata dari ecommerce sangat besar mengingat kondisi geografis Indonesia yang merupakan negara kepulauan di mana penduduk akan lebih mudah mengakses pasar yang belum pernah dicapai karena keterbatasan sarana dan prasarana transportasi. Jadi, tidak mengherankan jika salah satu yang paling penting dan sering dikeluhkan oleh investor dan pelaku bisnis di negara ini adalah proses distribusi dan logistik yang sangat tidak efisien (tidak efisien) dan berbiaya tinggi baik melalui darat, laut, dan udara.

E-commerce adalah salah satu jenis media jual beli online yang mulai berkembang dan sedang ramai dibicarakan oleh para pelaku bisnis. Implementasi e-commerce diakui mampu memberikan berbagai manfaat seperti kemudahan transaksi, sehingga transaksi dapat dilakukan kapan saja dan di mana saja (Limthongchai \& Speece, 2003).

\section{Berdasarkan beberapa} penelitian yang menunjukkan bahwa inovasi yang terkait dengan IT seperti e-commerce oleh UKM dapat memberikan berbagai manfaat signifikan bagi bisnis mereka, manfaat ini meliputi: UMKM dapat menyamakan kedudukan mereka dengan bisnis skala besar (Longenecker \& Moore, 2010), memfasilitasi komunikasi dengan pelanggan, dapat meningkatkan inovasi, produksi, penjualan dan layanan perusahaan (Kirzner, 2013) dan beberapa peneliti percaya bahwa dengan ecommerce, UMKM dapat berkontribusi dalam upaya meningkatkan daya saing produk lokal (OECD, 2016).

Selain berbagai manfaat yang dirasakan pebisnis untuk keuntungan ecommerce yang sukses, namun, tidak sedikit pebisnis yang belum tahu apakah ecommerce mereka telah mencapai kesuksesan dan bahkan banyak yang masih gagal (Hartman, 2002). Kendala mayoritas pebisnis saat ini adalah mereka tidak memiliki referensi yang baik untuk keberhasilan e-commerce, karena mereka masih menggunakan referensi yang dianggap tidak valid, seperti mengevaluasi keberhasilan e-commerce melalui jumlah hit halaman dan tampilan halaman (Kroll, 2000).

Penelitian ini dilakukan untuk menganalisis faktor-faktor yang menjadi penyebab keberhasilan adopsi e-commerce sebagai media jual beli online dalam meningkatkan daya saing usaha kecil dan menengah, khususnya di Kota Medan. Studi ini akan membandingkan keberhasilan atau kegagalan e-commerce yang sangat ditentukan oleh bagaimana perusahaan dapat meminimalkan faktor penghambat dan memaksimalkan pendorong keberhasilan. Faktor-faktor ini dikelompokkan menjadi 4 faktor, yaitu driver internal, driver eksternal, hambatan 
Volume 2. No.2 Agustus 2019 (100- 108)

Doi. 10.30596/liabilities.v2i2.3246

internal dan hambatan eksternal (Quaddus \& Achjari, 2015).

\section{METODE}

Populasi dalam penelitian ini adalah UMKM di Kota Medan yang telah menggunakan e-commerce sebagai media untuk membeli dan menjual produk mereka. Sampel adalah bagian dari populasi dengan kriteria spesifik yang digunakan sebagai sumber data penelitian (Cozby \& Bates, 2012). Populasi dalam penelitian ini tidak diketahui dengan jelas, sehingga jenis pengambilan sampel yang digunakan adalah purposive sampling. Kriteria pertimbangan tertentu untuk sampel adalah: 1) responden memiliki usaha kecil dan menengah yang terdaftar di akun e-commerce, 2) responden adalah UKM yang berdomisili di Kota Medan, 3) responden aktif melakukan transaksi dalam e-commerce setidaknya 6 bulan terakhir, 4) responden sudah memiliki pembeli di akun e-commerce. Formula lemeshow digunakan untuk populasi yang tidak diketahui dengan tingkat 10\% sehingga jumlah sampel dalam penelitian ini adalah 96 responden.

\section{HASIL DAN PEMBAHASAN}

Pemrosesan statistik deskriptif dibagi menjadi dua tahap dalam penelitian ini, yaitu: statistik deskriptif profil responden (demografi responden) dan statistik deskriptif instrumen penelitian (variabel). Berdasarkan demografi responden diketahui bahwa mayoritas responden dengan persentase 30,2\% adalah UMKM yang bergerak di bidang fashion, atau menjual barang-barang seperti pakaian, tas, sepatu dan sebagainya. Responden yang bergerak di bidang kuliner berjumlah $24 \%$, dan $21,9 \%$ bergerak di sektor kerajinan. Untuk e-commerce, UMKM yang paling banyak digunakan di Kota Medan adalah Shopee 43,8\% dan untuk Tokopedia dan Bukalapak 17,7\%. Dalam proses penghitungan statistik deskriptif untuk instrumen penelitian, diketahui bahwa rata-rata (rata-rata) jawaban pelaku UMKM untuk setiap variabel adalah sebagai berikut:

Tabel 1. Nilai Rata-Rata Responden

\begin{tabular}{|l|c|}
\hline \multicolumn{1}{|c|}{ Variabel } & Mean \\
\hline Internal drivers & 4,00 \\
\hline External drivers & 3,83 \\
\hline Internal obstacles & 3,91 \\
\hline External obstacles & 3,94 \\
\hline
\end{tabular}

Sumber: Hasil Penelitian, 2019 (Data diproses)

Hasil uji parsial dalam penelitian ini adalah sebagai berikut:

Tabel 2. Uji Parsial

\begin{tabular}{|l|r|r|r|r|}
\hline \multirow{2}{*}{ Model } & \multicolumn{2}{|c|}{$\begin{array}{c}\text { Unstandardized } \\
\text { Coefficients }\end{array}$} & \multirow{2}{*}{$\mathrm{t}$} & \multirow{2}{*}{ Sig. } \\
\cline { 2 - 4 } & \multicolumn{1}{c|}{$\mathrm{B}$} & $\begin{array}{c}\text { Std. } \\
\text { Error }\end{array}$ & & \\
\hline (Constant) & $-1,538$ & 1,427 & $-1,078$ &, 284 \\
\hline $\begin{array}{l}\text { Internal } \\
\text { Drivers }\end{array}$ & 1,455 &, 193 & 7,533 &, 000 \\
\hline $\begin{array}{l}\text { External } \\
\text { Drivers }\end{array}$ &, 527 &, 131 & 4,017 &, 000 \\
\hline $\begin{array}{l}\text { Internal } \\
\text { Obstacles }\end{array}$ &, 188 &, 155 & 1,216 &, 227 \\
\hline $\begin{array}{l}\text { External } \\
\text { Obstacles }\end{array}$ &,- 778 &, 243 & 3,199 &, 002 \\
\hline
\end{tabular}

Sumber: Hasil Penelitian, 2019 (Data diproses) 
Variabel driver internal (X1) memiliki pengaruh positif dan signifikan terhadap keberhasilan e-commerce, di mana nilai koefisien thitung $>$ ttabel, $7,533>1,661$ pada signifikan 0,000 $<0,05$, menyimpulkan bahwa hipotesis penelitian H1 diterima. Variabel driver eksternal (X2) memiliki pengaruh positif dan signifikan terhadap keberhasilan e-commerce, di mana nilai koefisien thitung $>$ ttabel, 4,017> 1,661 pada signifikan $0,000<0,05$ disimpulkan bahwa hipotesis $\mathrm{H} 2$ diterima. Variabel hambatan internal (X3) tidak signifikan untuk keberhasilan e-commerce, di mana nilai koefisien thitung <ttabel, 1,216 $<1,661$ pada signifikan $0,227>0,05$ menyimpulkan bahwa hipotesis penelitian H3 ditolak. Variabel hambatan eksternal (X4) memiliki pengaruh negatif dan signifikan terhadap keberhasilan e-commerce, di mana nilai koefisien $\mathrm{t}$ hitung $>\mathrm{t}$ tabel, $3,199>1,661$ pada signifikan 0,002 $<0,05$ menyimpulkan bahwa hipotesis penelitian $\mathrm{H} 4$ diterima.

Berikut ini adalah hasil pengujian simultan dari penelitian ini sebagai berikut:

Tabel 3. Uji Simultan

\begin{tabular}{|l|r|c|c|}
\hline Model & \multicolumn{1}{|c|}{ Df } & F & Sig. \\
\hline Regression & 4 & 67,765 &, $000^{\mathrm{b}}$ \\
\hline Residual & 91 & & \\
\hline Total & 95 & & \\
\hline
\end{tabular}

Sumber: Hasil Penelitian, 2019

(Data diproses)

Nilai koefisien $F=67,765$ pada 0,000 diperoleh. Sedangkan jumlah sampel penelitian adalah $\mathrm{n}=80$ dimana $\mathrm{df}(1)=\mathrm{k}$ $1=5-1=4$ dan $\mathrm{df}(2)=\mathrm{n}-\mathrm{k}=96-5=91$ diperoleh dengan nilai koefisien Ftable $=$ 2.47 pada signifikan 0, 05. Dengan demikian dapat disimpulkan bahwa driver internal, driver eksternal, hambatan internal, hambatan eksternal bersama-sama memiliki pengaruh yang signifikan terhadap keberhasilan UMKM e-commerce di Kota Medan. Nilai koefisien Fhitung $>$ Ftabel, 67,765 $>2,47$ pada signifikan 0,000 $<0,05$.

Koefisien determinasi dilakukan untuk mengetahui kemampuan variabel independen untuk dapat menjelaskan variabel dependen.

Tabel 4. Uji Koefisien Determinasi

\begin{tabular}{|c|r|r|}
\hline \multicolumn{3}{|c|}{ Model Summary } \\
\hline $\mathrm{R}$ & R Square & $\begin{array}{c}\text { Adjusted } \mathrm{R} \\
\text { Square }\end{array}$ \\
\hline, $865^{\mathrm{a}}$ &, 749 &, 738 \\
\hline
\end{tabular}

Sumber: Hasil Penelitian, 2019 (Data diproses)

Koefisien R square (R2) yang disesuaikan sebesar 0,738 menunjukkan bahwa keberhasilan e-commerce di Medan dapat dijelaskan oleh driver internal, driver eksternal, hambatan internal, dan $73,8 \%$, sedangkan sisanya $26,2 \%$ dapat dijelaskan. oleh variabel lain di luar ruang lingkup penelitian ini.

\section{Internal Driver terhadap Kesuksesan E-Commerce.}

Hasil statistik deskriptif driver internal mengungkapkan bahwa kepemimpinan biaya memiliki nilai ratarata tertinggi 4,16 atau UMKM diuntungkan dari e-commerce terkait dengan efisiensi biaya pengeluaran. 
UMKM dapat menghemat biaya promosi, biaya sewa tempat, biaya tenaga kerja, dan biaya layanan lainnya. Kepemimpinan Biaya adalah strategi perusahaan dengan meminimalkan biaya. Valipour, Hamid Birjandi \& Samira Honarbakhsh (2012) menjelaskan bahwa perusahaan dengan penerapan kepemimpinan biaya menunjukkan bahwa leverage keuangan, strategi bisnis dan dividen pembayaran akan memiliki efek positif pada kinerja bisnis. Biaya adalah salah satu faktor yang mempengaruhi UMKM di Indonesia dalam mengadopsi e commerce. Biasanya semakin murah biaya teknologi yang digunakan, semakin cepat akan diadopsi dan diimplementasikan dalam suatu organisasi (Premkumar \& Robert dalam Rahayu \& Day, 2015). Berdasarkan statistik inferensial diketahui bahwa driver internal memiliki efek positif dan signifikan terhadap keberhasilan e-commerce. Ini menunjukkan bahwa semakin tinggi driver internal, semakin tinggi tingkat keberhasilan e-commerce.

\section{External Driver terhadap Kesuksesan E-Commerce.}

Hasil statistik deskriptif variabel driver eksternal diketahui memiliki waktu yang dihabiskan memiliki nilai rata-rata tertinggi 3,96 atau UMKM diuntungkan dari e-commerce untuk pihak eksternal (konsumen) dalam mencari informasi terkait produk bisnis UMKM. dengan memanfaatkan ecommerce, konsumen dapat menghemat waktu dan biaya perjalanan karena mereka dapat mengunjungi toko yang sama secara virtual, hanya dengan beberapa klik. Dalam hal ini, e-commerce dapat membantu UMKM dalam meningkatkan nilai pelanggan, yaitu perbandingan antara manfaat (benefit) yang dirasakan untuk suatu produk dan biaya yang harus dikeluarkan untuk mendapatkan produk tersebut. Semakin besar manfaat yang diberikan dibandingkan dengan harga, semakin besar nilai yang didapat pelanggan untuk produk tersebut, Kotler dan Keller (2012: 136). Berdasarkan statistik inferensial diketahui bahwa driver eksternal memiliki efek positif dan signifikan terhadap keberhasilan e-commerce. Ini menunjukkan bahwa semakin tinggi driver eksternal, semakin tinggi tingkat keberhasilan e-commerce.

\section{Internal Obstacles terhadap Kesuksesan E-Commerce.}

Hasil statistik deskriptif variabel hambatan internal diketahui bahwa keahlian memiliki nilai rata-rata tertinggi 4,17 atau UMKM merasakan hambatan dalam memperbarui keterampilan yang terkait dengan aplikasi e-commerce. Kesiapan teknologi terdiri dari teknologi infrastruktur dan personil teknologi informasi (Zhu \& Kraemer, 2015) dan keduanya mutlak diperlukan jika perusahaan ingin mengadopsi e-bisnis sebagai bagian integral dari rantai nilai. (Tiago \& Maria, 2010). Sebagian besar adopsi e-commerce oleh UMKM secara luas tergantung pada penerimaan pemilik bisnis pada teknologi e-commerce.

Ini sangat masuk akal karena 
secara struktural UMKM cenderung memiliki manajemen terpusat, karena pemilik / manajer bisnis memiliki peran penting dalam pengambilan keputusan (Nguyen \& Waring, 2013). Yang penting adalah jika pemilik bisnis memahami dengan baik fungsi dan manfaat adopsi e-commerce, mereka akan lebih cepat untuk mengadopsi (Rahayu dan Day, 2015). Berdasarkan statistik inferensial diketahui bahwa hambatan internal tidak berpengaruh signifikan terhadap keberhasilan ecommerce. Hasil ini terlihat dalam kebijakan pemerintah untuk mendorong UMKM Indonesia untuk dapat menembus pemasaran digital atau e-commerce dalam programprogram e-smart. Program ini diprakarsai oleh Departemen Perindustrian dan Perdagangan dengan memanfaatkan kerja sama dengan pasar dan mitra perbankan sehingga pemain UMKM dapat memasuki pasar online dengan lebih mudah. Namun, hanya $37 \%$ dari UMKM hanya memiliki kapasitas pemasaran online dasar seperti akses komputer dan broadband, $18 \%$ sisanya dari UMKM memiliki kapasitas online sedang karena mereka dapat menggunakan situs web dan media sosial, dan hanya 9\% yang memiliki kapasitas pemasaran yang canggih, Deloitte (2015). Kendala terbesar yang dihadapi oleh UMKM adalah kurangnya produk berkualitas yang dipasarkan sehingga tidak dijual di pasar, Harmawan (2018).

\section{External Obstacles terhadap Kesuksesan E-Commerce.}

Hasil statistik deskriptif variabel hambatan eksternal diketahui biaya biaya memiliki nilai rata-rata tertinggi 4,14 atau e-commerce membuat beban yang harus ditanggung oleh konsumen meningkat seperti biaya pengiriman barang. Berdasarkan statistik inferensial diketahui bahwa hambatan eksternal memiliki efek negatif dan signifikan terhadap keberhasilan e-commerce.

Dalam beberapa e-commerce kita sering menemukan bahwa beberapa penjual bebas biaya pengiriman di Indonesia. Mendengar ini, tentu saja akan menguntungkan pembeli, karena biaya pengiriman yang menjadi beban tambahan bagi pembeli akan hilang. Ini adalah trik pemasaran yang dilakukan oleh e-commerce dan UMKM di dalamnya karena pada dasarnya biaya pengiriman ongkos kirim sudah termasuk dalam biaya produksi produk. Hasil penelitian ini bertentangan dengan penelitian dari Ningtyas et al. (2015) menyatakan bahwa hambatan eksternal memiliki efek positif pada adopsi ecommerce.

\section{KESIMPULAN DAN SARAN}

\section{Kesimpulan}

Internal driver memiliki pengaruh positif dan signifikan terhadap keberhasilan e-commerce. UKM setuju bahwa ecommerce dapat memberikan manfaat kepada mereka, terutama mengenai cost leadership, UKM dapat mengurangi biaya produksi sehingga harga dapat bersaing dan laba operasi dapat meningkat. external 
driver memiliki efek positif dan signifikan terhadap keberhasilan ecommerce. UKM setuju bahwa ecommerce dapat memberikan manfaat kepada konsumen, terutama yang berkaitan dengan waktu yang dihabiskan, sehingga memudahkan pihak eksternal (konsumen) untuk mencari informasi mengenai produk bisnis UKM. Hambatan internal tidak memiliki pengaruh yang signifikan terhadap keberhasilan e-commerce. UKM tidak memiliki keahlian dalam memperbarui keterampilan yang terkait dengan aplikasi e-commerce, sehingga implementasi program e-smart yang diluncurkan oleh Departemen Perindustrian hanyalah sebagian kecil dari UKM yang produknya sukses di pasar online. Hambatan eksternal memiliki efek negatif dan signifikan terhadap keberhasilan e-commerce. Meskipun cakupan pemasaran yang lebih luas dari UKM melalui ecommerce akan meningkatkan biaya pelanggan.

\section{SARAN}

UKM di Kota Medan perlu meningkatkan kepemimpinan biaya dan waktu yang dihabiskan untuk mendapatkan kesuksesan dalam ecommerce, serta meningkatkan pendorong internal dan eksternal lainnya. Ini dapat ditingkatkan dengan memberikan harga yang lebih kompetitif dengan mengurangi biaya produksi dan memberikan informasi lengkap tentang beberapa platform digital lain atau media sosial yang terkait dengan produk-produk UKM. Untuk meminimalkan hambatan internal dan hambatan eksternal, UKM dan Layanan Koperasi di Kota Medan bekerja sama dengan perusahaan pengiriman untuk mendapatkan harga khusus untuk UKM. Strategi kolaborasi pengiriman logistik diperlukan untuk layanan yang lebih baik.

\section{DAFTAR PUSTAKA}

Ardiyanto, Bagus. (2013). Analisis Bantuan Kredit Dari Program Kemitraan Dan Bina Lingkungan (PKBL) PT. Pelabuhan Indonesia III (Persero) Cabang Tanjung Emas Semarang Terhadap Perkembangan Usaha Mikro Kecil Di Kota Semarang. Diponegoro Journal of Economics, 2(3), 1-13.

Cozby, P. C., \& Bates, S. C. (2012). Methods in Behavioral Research. Singapore: Mc Graw Hill.

Deloitte. (2015). UKM pemicu kemajuan Indonesia: instrument pertumbuhan nusantara. Deloitte Access Economics. Australia.

Hartman, A. (2002). Net Ready. 1st edition ed. United States: McGraw-Hill Companies.

Harmawan, Bagus Nuari (2018, 25 Oktober). Hambatan UMKM Go Online. Dikutip 18 Juni 2019 dari https://news.detik.com/kolom/d4272888/hambatan-umkm-goonline.

Wong, Jony. (2010). Internet Marketing for Beginners. Jakarta: PT Elex Media Komputindo. 
Kirzner, M. I. (2013). Competition and Entrepreneurship. New York: Liberty Fund.

Kotler, Philip., \& Keller, K. L. (2012). Marketing Management. Edisi 14. Global Edition. New Jersey: Pearson Prentice Hall.

Kristiadi, Novi. (2017, 15 Agustus). E-Commerce, Manfaat dan Keuntungannya. Dikutip 19 Juni 2019 dari https://www.kompasiana.com/n ovikristiadi/5992634e93be2508 e06c5402/e-commerce-manfaatdan-keuntungannya.

Kroll, K, M. (2000). Beyond Hits. I-merchant, June, 25 - 28.

Limthongchai, Passachon., \& Speece, Mark. (2003). The Effect of Perceived Characteristics of Innovation on E- Commerce Adoption by SMEs. The College of Information Science and Technology, 2(3), 192-221.

Longenecker, J., \& Moore, C. (2010). Small Business Management: An Entrepreneurial Emphasis. New York: SWC Publishing.

McLeod Pearson. (2008). Sistem Informasi Manajemen. Jakarta: Salemba Empat.

Nguyen, T.H. \& Wearing, T.S. (2013). E-Commerce adoption of customer relationship management (CRM) Technology in SME's: an empirical study. Journal os Small Business \& Enterprise Development, 20(4), 824-848.

Ningtyas, PK., Sunarko B, Jaryono. (2015). Analisis Faktor yang Mempengaruhi Adopsi E-Commerce dan Pengaruhnya terhadap Kinerja UMKM. Jurnal Performance, 21(1), 1 Maret 2015.

OECD. (2016). The Economic and Social Impact of electronic Commerce: Preliminary Findings and Research Agenda (Notations Edition ed.). Februari. Organization for Economic Cooperation and Development. Paris, France.

Quaddus, M., \& Achjari, D. (2015). A Model For Electronic Commerce Success. Elsevier (Telecomunication Policy), (26), 127 - 152

Rahayu, Rita \& Day, John. (2015). Determinant Factors of E Commerce Adoption bu SMEs in Developing Country : Evidence from Indonesia. Procedia- Sociial \& Behavioural Science, 195(2015), 142-150.

Simamora, Henry. (2003). Membongkar Kotak Hitam Perilaku Konsumen. Jakarta: PT. Gramedia Pustaka Utama.

Steele, B. (2013, Mei). Selling Your Product On The Internet Just Became a Whole Lot Easier. Dikutip 18 Juni 2019 dari http://www.wavecentric.com/flexibl e-pricing-is-it-good-for-ecommerce/ Strauss, J., \& Frost, R. (2013). EMarketing. (7th Edition). New Jersey: Prentice Hall.

Suciani, Ratih Dwi. (2010). "Strategi 
Liabilities Jurnal Pendidikan Akuntansi

e-ISSN 2620-5866

Volume 2. No.2 Agustus 2019 (100- 108)

Doi. 10.30596/liabilities.v2i2.3246

Bersaing Bisnis E-Commerce

dalam Pilihan Alternatif Strategi

Generik". Tesis. Program Pasca

Sarjana Ilmu Administratsi.

Universitas Indonesia.

Sugiyono. (2011). Metode

Penelitian Kuantitatif, kualitatif dan R\&D. Bandung: Alfabeta.

Tiago, 0 \& Maria, F.M. (2010). Understanding e business adaption across inndustries in Europe countries. Industrial Management \& Data System, 110(9), 1337-1354.

Valipour, Hashem., Hamid Birjandi \& Samira Honarbakhsh. (2012). The Effects of Cost Leadership Strategy and Product Differentiation Strategy on the Performance of Firms. Journal of Asian Business Strategy, 2(1), 14-23.

Zhu,K, \& Kraemer,K. L. (2015). Post adopstions variations in usage and value of e business by organizations : cross country evidence from theretail industry. Informastion System Research, 16(1),61-84. 